\title{
Computing and Information Technology Challenges for 21st Century Financial Market Regulators
}

\author{
Theresa A. Pardo, Djoko Sigit Sayogo, and Donna S. Canestraro \\ 187 Wolf rd Suite 301, Albany, NY - 12205 \\ \{tpardo, dsayogo, dcanestr\} @etg.albany.edu
}

\begin{abstract}
This paper reports on a research effort designed to begin to systematically identify the most critical computing and information technology-related challenges facing financial market regulation activities. Computing and information technology adaptation in financial markets create a paradox. Information technology is needed for effective governing of financial markets, yet advances in information technology and the increasingly complex adaptations of that technology make it more difficult for regulators to have a clear picture of what is actually happening. Drawing on in-depth interviews with professionals from the financial market community, this paper outlines three primary challenges facing regulation efforts: 1) information sharing and integration, 2) mediating interrelationship among financial market constituents, 3) data-driven decision making. The paper concludes with recommendations for future research about the challenges and
\end{abstract}

Keywords: financial market, computing and information technology challenges, financial market regulators.

\section{Introduction}

This paper delineates critical Computing and Information Technology (CTI) related challenges facing financial market regulators in $21^{\text {st }}$ century financial markets. A U.S. General Accounting Report (2009) pointed to the complexity of financial market due to new and complex financial products and large and interconnected financial institutions and conglomerates [22]. The complexification of financial markets has led to intensive adaptation of advanced CTIs to improve financial market oversight mechanisms. The institutionalization of information technology transformed and changed the character and structure of financial market reflecting in the transactions processing, competition, innovation, [4] and also oversight. Financial market regulators as well have become increasingly dependent on computing and information technology to track, monitor, and analyze the large number of transactions in modern financial markets. Activity in and around the markets is increasingly based on data-driven decisions which rely on the use of computing and information technology.

The impact of technology depends on how it is used, regulated, and/or guided [2]. A report from a two year investigation by the Financial Crisis Inquiry Commission confirms that information technology and trading systems themselves are not the 
cause of the financial crisis, but the way in which technology is currently used, may be. Computing and information technology has shown its resilience toward external exposure and demonstrates great potential to complement the weakness of oversight mechanisms in expanding markets. For instance, the terrorist attack of September 11, 2001 showed the reliability of the disaster recovery capability of ICT-based financial systems [3] and the uncovering of the $\$ 64$ billion Ponzi scheme by Bernie Maddoff was made possible through the use of information technology [14]. On the other hand, the increasingly complex adaptations of that technology within the financial markets make it more difficult for regulators to create the necessary policies and practices necessary to monitor financial markets. This difficulty results in mismatches in the currency of market versus oversight and surveillance systems. Testimony given by Mary Schapiro, Chair of the Security Exchange Commission (SEC), on the flash crash of May 6, 2010, outline the challenges created by such a mismatch between technologies used in the process of market oversight and surveillance and the technologies and trading systems in financial market [19]. This situation obstructs regulators effort to develop clarity about what is actually happening. The risk of adopting new technologies is real, but often underestimated [24].

This paper reports on a research project designed to begin to systematically identify the most critical computing and information technology-related challenges facing financial market regulators. Drawing on in-depth interviews with financial market professionals, this paper outlines a preliminary mapping of the most critical information technology challenges facing $21^{\text {st }}$ century financial market regulators. Subsequently, this paper outlines a preliminary research agenda for studying the impact of information technology challenges on $21^{\text {st }}$ century financial market regulation. The rest of the paper is organized as follows. Section 2 briefly draws on the relevant literature to outline known CTI related challenges to financial market regulation and what is known about the impact of those challenges. Section 3 presents the research design and methods used, section 4 presents the results as well as the practical impact of the challenges for IT professionals. Section 5 outlines an agenda for future research. Finally, section 6 provides the conclusion.

\section{Literature Review}

\subsection{The Role of Computing and Information Technology in Financial Market Governance}

Hakken (2010) proposes four instrumental roles for CTIs in financial market [9]. The first role is CTIs as the enabler of rapid development of financial product innovations that exceed the threshold of transparent and perceptible structures of financial products $[5,23]$. The structure of financial products becomes so complex that assessing the transparency and risks becomes less feasible [26]. The intensification of financial innovations was due to the role of CTIs in channeling and disseminating two essentials ingredients of financial products, namely: new sources of funds with low interest rates and surging demands from global investors [26].

The second role is to mediate globalized markets. CTIs afforded the creation of "un-boundaried market in capital" through the development of international 
computing networks [9]. The globalization and boundary-less capital market resulted in escalating the unpredictability and uncertainty in the markets and challenges the "subjective boundary of financial regulators [9]".

The third role is complexification of risk assessment models. The current riskassessment models are no longer adequate to assess risks associated with rapidly developed financial innovation [9]. Hakken argues that the problem is on the tendency to perceive the result of computer-based risk assessment models as the "end" and not as "means" to judiciously aid competent professionals to assess the risks [9]. Arguably, richer information, such as: insights and expert analysis should complement computer-based-risk assessment [25]. Finally, Hakken contends that CTIs contribute to making asset values more ambiguous and obscure [9].

\subsection{The Primary Functions of CTIs}

This section will discuss three primary functions of CTIs recognized as challenges to financial market regulators, namely: 1) information sharing and information integration, 2) interrelationship among financial market institutions, and 3) high level and complex computing to support for data-driven decision making.

\section{Information Sharing and Information Asymmetry among Financial Market}

A number of studies have shown the significant value that stems from interorganizational information sharing in the private [11] and public sectors [7]. Interorganizational information sharing is regarded as one of the distinguishing core capabilities of modern ICTs [16].

Current literature outlines three possible benefits of information sharing among actors in financial markets, 1) diminish the potential of risk taking, 2) reduce information asymmetry, and 3) improve transparency [11]. Information sharing is important in improving risk management. Information sharing provides better benchmarks for risk assessment that will influence investors' risk behavior [10]. Information sharing is also important for financial market regulators to meet the primary objectives of ensuring the safety and soundness of the financial system and protecting stakeholders $[21,22]$.

Information sharing could also diminish information asymmetry among financial market actors. Information asymmetry emerges as a result of disconnected communication, internally or externally. A number of studies argue that information asymmetry will increase the likelihood of financial problem [8, 20]. Guillen and Suarez (2010) found that massive information asymmetry in the banking sector in the US and Europe result in decreased trust that lead to the recent financial crisis [8].

\section{Interorganizational Networks}

The advances of CTIs in the financial market had paradoxical impacts, creating global networking and challenging the governance and oversight mechanisms of financial markets. The potential benefits of information and communication technology to support the operation of network governance and collaboration has been highlighted in a number of studies $[5,6,17]$. The importance of network governance and collaboration is also acknowledged in the testimony of Mary Schapiro, in which she pointed out the significance of the coordination required to address inter-market manipulations and 
abuses and called a robust effort to build consolidated audit and tracking systems in the interconnected markets [19].

The inter-dependency in the current financial market regulations systems challenges the adequacy of its management and governance and leads to three possible caveats. 1) Regulatory and jurisdictional overlaps among regulators, 2) Complicated risk assessment, and 3) likelihood of systemic risks. First, a number of studies point at the mismatch between the market and regulators particularly in the United States [8, 20]. Regulations in the US financial markets are divided among agencies that regulate different financial market segments. Government agencies and Self Regulatory Organizations (SROs) share regulatory responsibilities that often overlap [22]. The overlapping regulations create problems since the resulting gaps in the US regulatory system can be manipulated by financial market actors. For instance, In the Senate Hearing on March 2009, Ben Bernanke stated that the crisis was also related to the fact that "AIG (The American International Group, Inc) [is able to] exploited a huge gap in the regulatory system" [8].

Second, networked governance increases the difficulties of predicting and assessing market risks $[13,25]$. Extensive global networks of sellers and buyers of financial products and cross-borders interdependency make it virtually impossible to tracks the associated risks [13]. The rapid development of financial innovation and interconnected markets can lead to gaps in technologies as well used for market oversight and surveillance against the technologies and systems used in the financial market [19].

Finally, interconnectivity increases the likelihood of systemic risks [13]. The development of ICTs results in stronger global financial linkages that lead to increases in the likelihood of creating systemic risks $[13,20]$. Initial tremors in a local market could easily reverberate globally [13].

\section{Information Processing and Data Driven Decision Making}

CTI development affords a high level computing and data processing which affects financial market regulators in two ways. First, regulators increasingly rely on quantitative measurement performed by "Quants" , for oversight and decision making. Second, risk assessment becomes more complicated due to risky products. These two issues are interrelated, in the sense that both point at the complications for market oversight mechanisms and decision making for the regulators.

Complicated oversight mechanisms arguably lead to increased reliance on quantitative indicators for risk assessment and market surveillance. The limitation of increased reliance on quantitative indicators for risk assessment is the inaccuracy of models used to reflect the actual risk of a financial product or in a market. The behavior of the market is shaped by various influences, some of which are unquantifiable, these might not be fully captured in the structured data [15]. The computational efforts using structured data are still inadequate to capture the inherent risks in recent financial innovation and might potentially augment the cost of asymmetric information [1].

\footnotetext{
1 "Quants" are mathematical gurus, who build mathematical models to exemplify the financial risks in the financial product innovation [18].
} 


\section{Research Design and Methodology}

\subsection{Research Design}

This research employs semi-structured interviews and focus group discussion. This approach enabled researchers to gain in-depth understanding and experiences of knowledgeable individuals expertly involved in financial market. Five organizations and approximately 25 individuals participated in individual face to face or phone interviews and focus groups. The larger set of interviewees minimize the problematic data bias pertain to qualitative research. The bias was also reduced by the fact that the interviewees are selected from different functions and different industries in financial market.

\subsection{Interview Profile}

The team of researchers interviewed 25 participants encompassing various components of financial markets. Specifically, 7 participants from investment banking, 4 participants from broker-dealer units of nation-wide insurance company, one interviewee came from market analyst and research, two interviewees were from the financial guarantee industry, and 11 were from self-regulatory organizations. The interviewees described their positions as related to general counsel, compliance function, legal department, or information technology.

\subsection{Interview Procedure}

Each interview lasted an average of between 45 minutes for interviews and 1 hour 20 minutes for group discussion. The interviews/group discussions were conducted separately, four by a face-to-face meeting and four by phone interview. A notification by phone and email was sent to each interviewee before each interview. During the interview, the participants were presented with one major question; What are the most critical challenges facing by financial market actors in the $21^{\text {st }}$ century? After each challenge was identified, interviewees were asked to clarify and elaborate each challenge and to reflect the challenge to their organization. Subsequently, the interviewees were asked to rank the challenges according to their perceived level of importance to their organization. Although the numbers of interviewee were not large, the interviews were sufficiently in-depth thus generate a significant amount of data.

\section{Result}

Common themes across the challenges were identified from interview transcripts (See table 1). Three primary CTIs related challenges were identified. The following sub-sections discuss the challenges within each theme. Quotes from the interviews and focus groups are provided to support the theme development.

\subsection{Information Sharing and Integration}

The focus group discussions and interviews indicate majority agreement on the significance of information sharing issues. This analysis identified five inter-related challenges within the context of information sharing and integration (See table 1). 


\section{Disparate Legacy System}

The interviewees noted that the banking industry has undergone a substantial numbers of mergers and acquisitions resulting in a number of disparate legacy systems. One interviewee from a Broker-Dealer pointed out that integrating legacy systems is a major hurdle for organizations. These efforts brought together many different firms along with their legacy systems resulting in a variety of systems that don't "talk to each other" and various "gold copies"; copies of data captured at different level and organization. This results in restrictions on information sharing and undermines efforts to eliminate inter-market manipulations.

Table 1. Impact of $21^{\text {st }}$ Century Challenges for IT

\begin{tabular}{|c|c|c|}
\hline Theme & Challenges & Potential CIO/IT function Impact \\
\hline Information & - Disparate legacy sys- & - Reconciliation of the data and system \\
\hline Sharing and & tem & - Ensuring data quality (reliability, rele- \\
\hline Integration & - Cost of compliance & vancy, \& timeliness) \\
\hline & $\begin{array}{l}\text { - Strict Information } \\
\text { sharing policy } \\
\text { - Keeping up with the } \\
\text { changes in regulations }\end{array}$ & $\begin{array}{l}\text { - Interpreting changes in regulations } \\
\text { - Balancing regulatory change, invest- } \\
\text { ment plan, cost of compliance, and IT } \\
\text { budget. }\end{array}$ \\
\hline $\begin{array}{l}\text { Interorganiza- } \\
\text { tional network }\end{array}$ & $\begin{array}{l}\text { - Interdependency and } \\
\text { overlaps of financial } \\
\text { market regulators } \\
\text { - Managing conflict of } \\
\text { interest }\end{array}$ & $\begin{array}{l}\text { - ICTs for network governance. } \\
\text { - ICTs for networked risk assessment. } \\
\text { - ICTs for collaboration, coordination, } \\
\text { and relationship-building. }\end{array}$ \\
\hline $\begin{array}{l}\text { Information } \\
\text { processing and } \\
\text { Data driven } \\
\text { decision making }\end{array}$ & $\begin{array}{l}\text { - Information processing } \\
\text { - Data monitoring }\end{array}$ & $\begin{array}{l}\text { - Data relevancy for risk assessment. } \\
\text { - Complementing structured data analysis } \\
\text { with non-structured analysis. } \\
\text { - a reformed quants }\end{array}$ \\
\hline
\end{tabular}

2. Keeping up with changes in regulations, financial privacy, and cost of compliance

Keeping up the changes in regulations and compliance as well as new and changing privacy requirements represent the second set of major challenges. An interviewee from an investment bank notes the sheer numbers of policy changes they have to comply with - "at anytime the SROs have 2 dozens proposals to change rules". The legacy systems, onerous rules and regulations lead to difficulties in using IT to deal with compliance responsibilities. This set of conditions is a major hurdle especially for small institutions. Keeping up with the changes of regulations can be very costly and need to be budgeted well in advance.

\section{Integrating business and technology units}

The need to integrate business and technology units to support intra-organizational information sharing is another issue. The data indicates the classic case of disintegration between IT and business units. The IT people and business unit people need to, but do not, talk to each other and nor do they have a common language to faciliate information sharing. One of the interviewees emphasized "technology is 
there, most IT skills are there, business knowledge and experience are real challenges". A certain level of IT fluency is important. Interviewees spoke to the need for understand the role, application, and architecture of technology aoutlining $\mathrm{s}$ well as challenges around data quality and integrity, knowledge of the architecture of systems and work flow.

\subsection{Interorganizational Network}

The majority of the interviewees asserted the importance of addressing interconnectivity and interdependency among financial regulation systems. The regulation of the United States financial markets is divided among agencies that regulate the different financial market segments and often overlap. Companies engaging in multiple financial markets find themselves regulated by different institutions with different approaches to regulation.

The interviewees from investment banking pointed out the duplication and overlap of regulations that result in a large number of inefficiencies and lack of coordination among the regulators. For instance, according to the interviewees, NYSE, FINRA, and SEC send very similar inquiries which require separate efforts to respond. These overlaps in regulations lead to redundancy in efforts to ensure compliance with regulations thus inducing higher costs for compliance.

Interviewees from insurance and broker-dealers, noted that interdependency sometimes creates competition within regulations/regulators. The regulators compete with each other to be the first to protect consumers, identify fraud creating inconsistencies, and appeal to the public. This competitiveness among regulatory agencies poses a problem for financial firms as they work to comply with various regulations. The financial firms often have to marry various strict rules imposed by different agencies. The overlaps in financial regulations create confusions for firms to choose which one to focus on and to follow. As an example, the interviewee from investment bank mention that "eight option exchanges have different rules, [so] which do you use as the right one in monitoring systems".

The interviewees from self-regulatory organization (SROs) also point at the same issue. The SROs highlight "reputational risk" as one of their primary risk. The reputational risks relate to the risk of being relevant to the market and risk of losing power over the market. As asserted by one of the interviewee, "I think one of the greatest challenges right now is remaining relevant, there is a lot of works going on as the result of regulatory reform...that could jeopardize the organization as the whole...is the business gonna move from cash security to swap such that SRO's B gain a lot more power and SRO's A roles are minimize". Negotiation of power and power dependencies are considered as characteristics of networked governance.

The interviewees from SROs also expressed concern about the impact of these interdependencies on the risk assessment. They especially noted concerns about future efforts of regulators to evaluate risks. Informed risk analysis is important, but in the case of networked systems, regulators, the interviewees agreed, also need to understand the interdependencies and dealing with multiple regulatory schemes. As interviewees from the SROs put it, "[it is] hard to know how firms are morphing their behaviors in areas we don't have access to...". 


\subsection{Information Processing and Data Driven Decision Making}

One interviewee from the financial guarantee industry described the problem associated with integrated data and information sharing as "no one on the other end would know what to do with that information". Implied in this statement are the challenges of processing and interpreting the data and information. Interviewees from the investment bank, insurance companies, and broker-dealer all emphasized the increasing volume of data. They noted an exponential growth of trading information and data as result of current high-tech trading systems. This concern was found to be more imminent for financial regulators as compared to other actors of financial market.

For financial regulators, information processing involves collecting data and figuring out how to interpret it. Having large amounts of intricate financial market information leads to several possible issues for information processing. The first issue relates to the increase complexity in efforts to analyze the behavior of markets. Over the years, the regulation has changed from prescriptive to less prescriptive and become more contextual. The regulations they noted, have become too broad, too general, and offer alternatives. As result, the information collected by regulators is more complex and creates problems when analyzing market behavior and in particular when trying to understand cause and effect relationships. It is more difficult now they noted, for analysts to connect the aggressive behavior of some firms to the current economic crisis. .

The second issue relates to the difficulties of identifying the relevancy of data or information. One interviewee indicated that expanded filing requirements yields different types of information which lead analysts to question the relevancy of data. The example given by the interviewee is corporate bonds in which there is no way to differentiate among the bonds. As a result, there is different information and different granularity of data that complicates the processing of information.

The third issue noted by interviewees from self-regulatory agencies is that the limitation created by reliance on quantitative indicators or "quants" for risk assessment. "Quants" are mathematical gurus who build mathematical models to exemplify the financial risks in the financial product innovation or/and command excellent ability to perform quantitative analysis [18]. They assert that the problem with "quants" is that "they cannot marry the practical with the theoretical". For instance, quants are concerned only with measuring quantitatively the high yield of bond market and raise concern about it. However, according to the interviewees, the quants do not connect the dots to consider about what to do with the information. This issue also points at the requirements to have integrated skills for IT professionals/graduates. Financial or information technology skill alone is not adequate to deal with the future challenges of financial market.

\section{Discussion}

As discussed above, analysis of the interviews and focus group discussions identified three primary CTI related challenges for $21^{\text {st }}$ century financial market regulators: 1 ) information sharing and integration, 2) mediating interrelationship among financial market constituents, and 3) data-driven decision making. The challenges also serve as the framework for the recommendations for future research presented below. 


\subsection{Information Sharing and Information Asymmetry}

This research identified the need to foster information sharing across financial market constituents. Well-designed and executed information sharing is necessary for improving risk assessment and risk management. There is the need to have closer working relationship, discussion, and communication among financial regulators, IT professionals, and financial firms. One of the interviewees described the communication between regulators and firms that used to exist and currently missing.

"regulator of the [this organization] used to come in like in 2000, they use to meet [with me] annually and then they would ask about credit default swaps and wrapping this and wrapping that...I was impressed they were asking some reasonable questions and then nothing ever happen with that sort of like their academic division...[interview result]"

Disconnected communication, both internally inside organizations and externally among financial market actors could result in information asymmetry. In support to the Houston's argument [11], information sharing could diminish the information asymmetry and increase transparency among actors of financial market. Research is needed to address this situation.

Future research could address current limitations in integrating and making effective use of existing information and limitations in creating integrated communication among financial market constituents. A comprehensive understanding of the information sharing structure of the financial actors (in particular financial regulators) is needed to identify factors that can obstruct information sharing and therefore hinder effective prudential regulation, consumer protection and, in general, reduction of the systemic risks. Venue for future research could also assess the needed capabilities to foster close working relationship and communication among financial market constituents. Among others, possible sample questions that new research could explore are:

1. What kinds of information sharing mechanisms are presently used among the financial regulatory agencies?

2. What are the challenges of integrated communication and information sharing among financial market regulators/actors?

3. What kinds of capabilities are needed to have effective cross-boundary information and data sharing among financial market regulators/actors?

4. What kinds of critical success factors are required to better account for variations in the capabilities of actors in the networked financial market?

\subsection{Interorganizational Network}

Networks of actors that trust each other and share information are the foundation for more advanced systems of information sharing and information integration. However, governance by networks comes with problems and challenges. This research found the importance of addressing challenges of interconnectivity and interdependency particularly among financial market regulators. The interdependency could create negative impacts for financial market in the sense of 1) increase redundancy and information overlaps, 2) create competitiveness among regulators, and 3) complicate risk assessment process. 
This research found several avenues for future research in relation to the interdependency among financial actors. First, the concern of regulators in evaluating risk in the network system. In accord to Hakken's finding [9], the interdependencies restrict the ability to analyze across regulators. Business is regulated by different regulators thus performing complete risk assessment require bridging the regulatory boundary. This complex network of relationships accentuates the need to evaluate the effective mechanism of collaborative network of public-private partnership to keep up with the rapid changes in financial innovations and regulations.

Second, interdependency might lead to competition among regulators that could create mismatch between market and regulators. Globalized financial network raise challenges to the "subjective boundary of financial regulators [9]". Complex relationships between many semi-autonomous organizations in the financial market result in competition, cross jurisdictions, and power negotiations and exploitation. Network analysis is needed to model and analyze the interactions among financial market regulators in the dynamic settings.

Third, financial market actors are connected to each other in complex social structures, locally and globally. This condition accentuates the necessity to have a deep exploration of the role of social networks to assess and representing the complexity of organizational social processes among financial market actors. Additionally, future research needs to investigate the influence of social interconnection among financial market actors in facilitating and/or inhibiting effective regulatory and supervisory systems. Thus, possible sample questions within this venue are:

1. What theories of social networks and social herding can inform research into the mechanism of interrelationship of financial market regulators/actors?

2. Does the current regulatory information sharing relationship structure pose challenges for ensuring the sound and safety of the financial system?

3. How can we model and represent the complexity of organizational and social processes that are useful for developing system for effective risks assessment and oversight mechanism in the networked financial market?

\subsection{Information Processing and Data Driven Decision Making}

This research found two major concerns related to information processing and computing, namely: massive volume of data and overreliance on quantitative measurement. Cutting edge computer technology affords processing of large amount of structured data through computing model. However, this research indicates that analyzing structured data is insufficient to capture the actual risk inherent in the financial market. Structured data may not be adequate to provide close approximation to the real-world scenario.

This research found that data and information interpretation for risks analysis and prediction of market behavior not only requires sophisticated analysis of structured data but also complementary of richer information. Several research proposed alternative approaches aim to provide close approximation to the real-world behavior by complementing the quantitative indicators with non-quantitative indicators $[12,15$, 20]. Nonetheless, future research is needed to assess the effectiveness of analyzing unstructured data, such as narrative reports and social media, as complementary of structured data analysis.

On the other hand, in many cases the information needed by actors in financial markets, particularly regulators, are available but not accessible in a meaningful way. 
A massive amount of data is sometime available, but extracting meaningful information from the data requires large effort that might not be economically or technically feasible. One issue that the interviewees pointed at is the need to have mix of skills and knowledge. For instance, business unit sometime does not have adequate skill about information technology for them to understand the challenges faced by IT units. This issue relates to the adequacy of the dimensions of capability of current college graduates and also professionals working in the financial market. College graduates might have a high ability but codified in their respective fields that restrict them to do an analysis in holistic and comprehensive way.

\section{Conclusion}

The analysis identified a set of practical implications for IT professionals and avenues for future research based on the critical CTIs related challenges identified in this preliminary research effort. Four major practical implications for IT professionals emerged from the analysis of the identified challenges. These practical implications are: 1) the need to have information and data management or strategies, 2) the important of budgeting and planning of IT expenditures, 3) the growing significance of networked governance, and 4) the increasing requirement for better monitoring and surveillance to ensure compliance.

This research was undertaken to begin to systematically identify and build new understanding of the primary CTIs challenges for financial market professionals. Three primary themes of CTIs related challenges identified in this paper are: 1) ability to facilitate information sharing and integration, 2) mediate interrelationship among financial market constituents, and 3) data-driven decision making. Four practical implications as well as four possible avenues for research related to the three primary themes of challenges emerged and are presented here as well. Considered together they create an approach for framing the research and practice challenges facing the $21^{\text {st }}$ century financial market community.

\section{References}

1. Arora, S., Barak, B., Brunnermeier, M., Ge, R.: \&Ge, R. Computational complexity and information asymmetry in financial products. In: Proceedings of the First Symposium on Innovations in Computer Science, ICS (2010)

2. Barry, C.: The Ethical Assessment of Technological Change: an overview of the issues. Journal of Human Development and Capabilities 2(2), 167-189 (2001)

3. Beck, R.: Can IT lean against the wind? Communications of the ACM 53(5), 38-40 (2010)

4. Cerny, P.G.: The dynamics of financial globalization: Technology, market structure, and policy response. Policy Sciences 27(4), 319-342 (1994)

5. Crotty, J(n.d.).: Profound Structural Flaws in the US Financial System that Helped Cause the Financial Crisis. Economic \& Political Review XLIV(13), 127-135

6. Dawes, S.S.: Interagency information sharing: Expected benefits, manageable risks. Journal of Policy Analysis and Management 15(3), 377-394 (1996)

7. Dawes, S.S., Cresswell, A.M., Pardo, T.A.: From Need to Know to Need to Share: Tangled Problems, Information Boundaries, and the Building of Public Sector Knowledge Networks. Public Administration Review 69(3), 392-402 (2009)

8. Guillén, M.F., Suárez, S.L.: The Global Crisis of 2007-2009: Markets, Politics, and Organizations. Research in the Sociology of Organizations 30, 257-279 (2010) 
9. Hakken, D.: Computing and the Crisis: The Significant Role of New Information Technologies in the Current Socio-economic Meltdown. TripleC 8(2), 205-220 (2010)

10. Han, K., Kauffman, R.J., Nault, B.R.: Innovator or owner? Information sharing, incomplete contracts and governance in financial risk management systems. In: Proceedings of the 37th Annual Hawaii International Conference on System Sciences, 2004, p. 10 (2004)

11. Houston, J.F., Lin, C., Lin, P., Ma, Y.: Creditor rights, information sharing, and bank risk taking. Journal of Financial Economics 96(3), 485-512 (2010)

12. Huang, M.L., Liang, J., Nguyen, Q.V.: A Visualization Approach for Frauds Detection in Financial Market. In: Presented at the 13th International Conference Information Visualization, pp. 197-202 (2009)

13. Hurlburt, G.F., Miller, K.W., Voas, J.M.: An Ethical Analysis of Automation, Risk, and the Financial Crises of 2008. In: IT Professional, pp. 14-19 (2009)

14. Hurtado, P.: FBI Uses Triage to Shift From Terror to Madoff, Subprime Probes - Bloomberg. Bloomberg (2008), http://www.bloomberg.com

15. Mahajan, A., Dey, L., Haque, S.M.: Mining Financial News for Major Events and Their Impacts on the Market. In: Presented at the WI-IAT 2008. IEEE/WIC/ACM International Conference on Web Intelligence and Intelligent Agent Technology, pp. 423-426 (2009)

16. Pardo, T.A., Gil-Garcia, J.R., Burke, G.B.: Governance structures in cross-boundary information sharing: Lessons from state and local criminal justice initiatives. In: Proceedings of the 41st Annual Hawaii International Conference on System Sciences, p. 211 (2008)

17. Pardo, T.A., Gil-Garcia, J.R., Burke, G.B.: Sustainable cross-boundary information sharing. In: Chen, H., Brandt, L., Gregg, V., Traunmuller, R., Dawes, S.S., Hovy, E., Macintosh, A., et al. (eds.) Digital Government: Advanced Research and Case Studies, and Implementation, pp. 421-438. Springer, New York (2008)

18. Salmon, F.: Recipe for Disaster: The Formula That Killed Wall Street. In: Wired Magazine (February 2009), http://www.wired.com/techbiz/it/magazine/

19. Schapiro, M.L.: estimony Concerning the Severe Market Disruption (May 6, 2010), http://www.sec.gov/news/testimony/2010/ts051110mls.htm

20. Sheng, A.: Financial Crisis and Global Governance: A Network Analysis. In: Spence, M., Leipziger, D. (eds.) Globalization and Growth: Implications for a Post-Crisis World, pp. 69-93. The World Bank, Washington (2010)

21. U.S. Government Accountability Office, Better Information Sharing Among Financial Services Regulators Could Improve Protections for Consumers (No. GAO-04-882R). Regulatory Information Sharing. Washington, DC (2004)

22. U.S. Government Accountability Office, Bank Secrecy Act: Federal Agencies Should Take Action to Further Improve Coordination and Information-Sharing Efforts (No. GAO-09227). Washington, DC (2009)

23. Vardi, M.Y.: The Financial Meltdown and Computing. Communications of the ACM 52(9) (2009)

24. Werner, M., Grief, H.: Calculating the Unknown. Rationalities of Operational Risk in Financial Institutions. TripleC 8(2), 237-250 (2010)

25. Wilkinson, J., Spong, K., Christensson, J.: Financial Stability Reports: How Useful During a Financial Crisis. In: Economic Review, Federal Reserve Bank of Kansas City (Spring), pp. 41-70 (2010)

26. Zandi, M.: Financial Shock: a 360o Look at the Subprime Morgage Implosion, and How to Avoid the Next Financial Crisis. Pearson Education, New Jersey (2009) 